\title{
Testing of Mobile Systems using Models
}

\author{
G.Kavitha C.Geetha, K. Anita Davamani
}

\begin{abstract}
We show a trial examination where exhibit based testing (MBT) was associated with a flexible structure: the Android client of QuizUp, the greatest compact inquiry and answer challenge on the planet. The assessment shows that standard MBT approaches in perspective on extended restricted state machines can be used to test a flexible application in a feasible and beneficial way. Non-irrelevant defects were recognized on a sent system that has countless customers and was by then all around attempted. The length of the general testing effort was of a quarter of a year, including the advancement of the models. Keep up ing a single social model for the application was enter with a particular ultimate objective to test it in a capable manner.
\end{abstract}

Keywords: QuizUp, MBT

\section{INTRODUCTION}

Testing of flexible systems (applications) is another test for rogramming associations. Versatile applications are of-ten available on different stages, working systems, programming vernaculars, etc. This makes it essential to ensure that the application demonstrations also self-governingly of the phase on which it runs and of what lingo is used. Moreover, compact systems consistently have various structure options that effect the manner in which they act. Thusly application designers must ensure that the application fills in clearly for different arrangements. Applications are routinely attempted physically. Such manual testing typi-cally relies upon the manual creation and execution of examinations that duplicate useful utilization of the application.

Manual testing is dull, and is most likely going to exhaust rather than careful, especially when a far reaching number of blends of utilization circumstances for various game plans must be verified. For each arrangement, the analyzer needs to physically enter data, physically swipe the screen, tap on gets, and physically differentiate the veritable result and direct and the ordinary one. Complexities among real and expected result and lead are then physically chronicled and uncovered as issues. It is in like manner very grim and pursuing for individuals to support the ordinary outcomes of a graphical UI (GUI) properly, in light of the way that the state tends to be uncommonly verbose. For example, for each screen or state in an application, there are ordinarily various segments to support. Difference and API testing, where one has fundamental bungle codes as responses.

Revised Manuscript Received on August 22, 2019.

G.Kavitha Department of CSE,Bharath Institute of Higher Education \& Research,TamilNAdu Email: kavithag90@gmail.com

C.Geetha, Department of CSE,Bharath Institute of Higher Education \& Research,TamilNAdu Email: gitakannan.2010@gmail.com

K. Anita Davamani, Department of CSE,Bharath Institute of Higher Education \& Research,TamilNAdu Email: anitadavamani@gmail.com

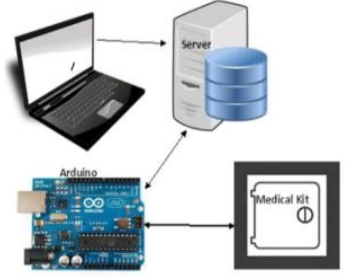

Fig: 1 Arduino Medical Kit

\section{MODEL BASED TESTING WITH STATE MACHINES}

\section{A. Model portrayals}

We used the EFSM style of demonstrating depictions since state machines are adequately un-derstood and particularly thought speculatively [22]. In addition, easy to-use open source gadgets that produce tests from them are practically available [16].Casually, an EFSM incorporates states and changes [22]. It contains a specific state, called the start state, where the machine starts selecting. Concerning MBT, a progress keeps an eye on a system lift, or action, that moves the customer beginning with one state of the structure then onto the going with. Such exercises could, for instance, be calling a system or clicking a catch. The states are used to familiarize affirmations with watch that the customer is in the basic structure state. These announcements are boolean verbalizations in light of the segment code that is ordinary from a particular strategy consider when a structure is in a particular state.

The EFSM show is a theory of the standard Finite-State Machine appear with watchmen or partner purposes of repression related with advances [12]. Guardians are boolean enunciations or limits that are surveyed in the midst of show traversal time. State components connect with one to store the chronicled perspective on traversal and can be used to embed test prophets in the model. In light of the evaluation of a watch, a model-researching instrument or estimation uniquely picks among the developments whose guardians are sat-isfied. Using EFSMs we can encode data parameters as parts instead of showing the data at the model level as changes or states. Such encoding can, for example, be done to parameterize, or instate, the model at the start of each traversal, confirming data as variables or other data structures. This draws in one to modify the data to be attempted without changing the model and as such it doesn't influence the proportion of states and advances in the model using EFSMs. In this manner, the model is positively not hard to review, handle, and advance. Additionally, gatekeepers and extra purposes of constrainment can be used to return data from exercises in setting on the present traversal history. 


\section{TESTING QUESTIONS}

\section{A. The displaying objective}

The major showing target was to plot the model so the translated investigations would be re-alistic yet wonderful while seeing the testing questions and picking if QuizUp is consistently reliable with the requirements. A minute showing goal was to plot the model in such manner that the got tests from the model could continue running on QuizUp's creation server. The age server has the live sort of the application that general customers can get to. That derives that we, as analyzers, don't have full control of the data space. New customers can build up, the QuizUp get-together can animate the blueprint of open subjects, and messages can rise sporadically from authentic customers. Consequently, we would need to plan the model in such manner that the recognized test code in the mapping ta-ble would not be dependent on unequivocal data in the application, in any case genuinely executed to separate sorts of data and select segments emphatically.

The third demonstrating goal was to administer customers with different degrees of progress. That is, the picked tests should not be in danger to a particular test customer or his status in the redirection. A hypothetical test customer could as such separate from being another customer who basically finished the course toward joining to being a moved customer who has played two or three beguilements.

\section{B. The QuizUp demonstrate as progressive EFSMs}

We showed the QuizUp application as a social affair of EFSMs that were managed in a dynamic structure using five layers to control adaptable quality. It legitimizes setting up that a few scenes in the application can be gotten to as sub-scenes from different scenes. For example, the Game-play scene can be gotten to from scenes, for instance, the Home scene, Topics scene and anything is possible beginning there. As such, the layer centrality of the Game-play scene itself can change subordinate whereupon scene offers access to it.

The most fundamental layer (see Figure 2) of the model is spun around using the Email Log-in or Email Sign-up scenes before entering the application's In-redirection scenes, where each state for these scenes fills in as an area state to the second layer of the model. The organization, consequently, unequivocally ensures that the "trap" customer (the assessment) has separate in before using any of the inside in-entertain features. Sporadic at any rate certifiable developments, for instance, unendingly entering and leaving these scenes, are potential outcomes from a passionate traversal of this model.

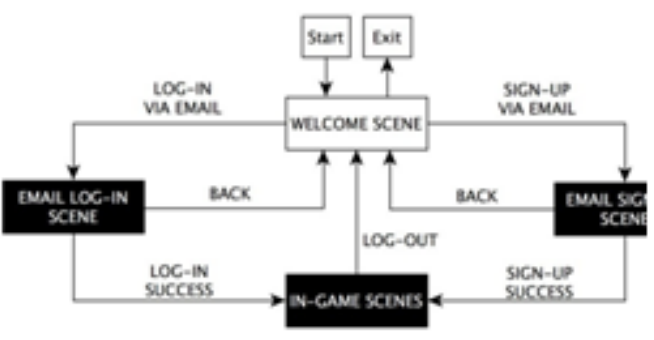

Figure 1: Highest layer of the model

Because of how we outlined out the most basic layer of the model, the second layer of the model is both revolved around the particularly orchestrated activities of stamping in or joining, and furthermore getting significantly highlights of the in-diversion scenes. The model is plot in such way that it looks at sensible, and besides bizarre, strategies for contributing the clients accreditations (email and secret key) so as to get to the application. Preceding contributing the accreditations, a "trick" test client is recovered from an association called QTDS (QuizUp Test Data Service), which was executed particularly for this key data (for instance name, title, nation) of various test clients in a JSON record. Likewise, the client headway level is logged by utilizing a partner limit, since some in-redirection scenes (for instance Messages scene) show different data relying on the progression of the client. The outline of the model honors tricky (testing of invalid groupings). In context on the documentation, we coordinated the sorts of messages and passwords that a client can enter. There are three sorts of messages to join; a liberal email, an email for a non-existing client (invalid), and a truly encompassed email (invalid). There are two sorts of passwords to join; a genuine puzzle word and an invalid watchword. The model allows any mixes for contributing these obvious sorts of messages and passwords.

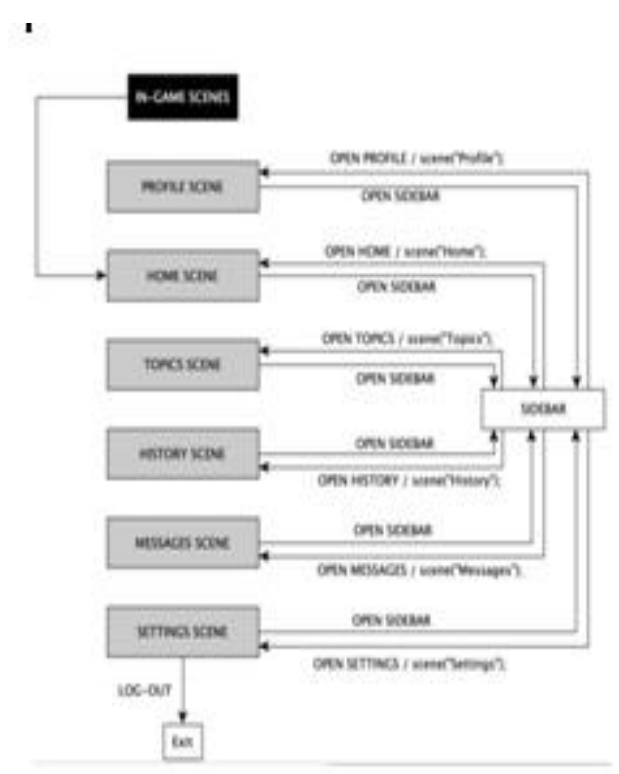

Figure2: Sub model for scenes in model

\section{GENERATION OF THEORETICAL EXPERIMENTS}

A model traversal heads near the start state in the most raised layer of the model and stops when a given ending measure is met. We used yEd12, to make the models in this evaluation and used Graphwalker to cross the models13. Graphwalker is an open-source Java library that produces test developments from FSMs and EFSMs that are, e.g., made using yEd models and set away in Graphml organize. Graphwalker offers stopping criteria, for instance, state development and progress scope. We used Graphwalker to make 100 novel appraisals with worked in approvals for inside features using the self-determined way check covering $100 \%$ of states and advances. 


\section{A. Mapping unique names to solid code parts}

We used Appium's Python library to chat with the QuizUp application. The code frag-ments for each etching in the QuizUp show were physically brought into the mapping table. We made a substance that accordingly tracks whether new states or advances were added to the model, and expecting this is the situation, it makes an association code part for new checks.

Notwithstanding the manner by which that QuizUp is a versatile system, it has certain similarities with non-accommodating structure we legitimately had a go at drawing in us to use the corresponding MBT approach yet again. The key indistinguishable quality is that QuizUp is a state-based structure, where the customer encouraged effort can be sketched out as courses of action of events as lifts and responses. This lifts response configuration empowered us to demonstrate the application as a state machine, which is the key piece of the MBT approach used as a touch of this examination. Most responsive systems can be portrayed correspondingly. Regardless, whatever structures don't give a nitty enough filthy response to all lifts, making it difficult to pick their state.

\section{CONCLUSION}

We will directly separate the QuizUp occurs with our latest assessment on GMSEC [10]. At the time of the QuizUp consider, we had snatched relationship in MBT which construed that we were altogether continuously fruitful in setting up the QuizUp consider (3 weeks stood out from 7 weeks in the past assessment). In light of the outcomes from the past assessment, we were likewise arranged to in a split second set up that EFSMs would be the most authentic model delineation for QuizUp without first endeavoring different things with FSMs. When looking model size (for instance measures of states and advances) for GMSEC and QuizUp, plainly the QuizUp show is broadly more noteworthy. The GMSEC show contained 49 states and 62 drives while the QuizUp show included 125 states and 192 changes.

The purpose for the capability is twofold. From the outset, we endeavored a more significant number of highlights for QuizUp than for GMSEC and, moreover, in QuizUp, we could recover progressively sorted out data about the condition of the structure at some arbitrary time. In QuizUp, for instance, mess up messages (content strings showed up in the GUI) were autonomous for various conditions or courses of action. Then again, for GMSEC, we basically utilized central API return codes to articulate whether an activity ought to be incredible or not.

There are 8 mentioning and 15 affirmations for the GMSEC appear, in any case 87 demands and 74 authentications for the QuizUp show up. The explanation for the monstrous separation is that a state in GMSEC mirrors the run of the mill lead of the framework after a specific API procedure call, anyway a state in QuizUp is contained various UI fragments that shaped a view or a scene in the application. Thusly, for several states in QuizUp, we expected to underwrite unmistakable UI parts, and information, with a specific genuine goal to make certain that we were in truth in a specific state.

\section{REFERENCES}

1. Gowri Sankaran, B., Karthik, B. \& Vijayaragavan, S.P. 2019, "Weight ward change region plummeting change for square based image huffman coding", International Journal of Innovative Technology and Exploring Engineering, vol. 8, no. 10, pp. 4313-4316.

2. Gowri Sankaran, B., Karthik, B. \& Vijayaragavan, S.P. 2019, "Image compression utilizing wavelet transform", International Journal of Innovative Technology and Exploring Engineering, vol. 8, no. 10, pp. 4305-4308.

3. Kandavel, N. \& Kumaravel, A. 2019, "Offloading computation for efficient energy in mobile cloud computing", International Journal of Innovative Technology and Exploring Engineering, vol. 8, no. 10, pp. 4317-4320.

4. Vinoth, V.V. \& Kanniga, E. 2019, "Reversible data hiding in encrypting images-an system", International Journal of Engineering and Advanced Technology, vol. 8, no. 6, pp. 3051-3053.

5. Selvapriya, B. \& Raghu, B. 2019, "Pseudocoloring of medical images: A research", International Journal of Engineering and Advanced Technology, vol. 8, no. 6, pp. 3712-3716.

6. Senthil Kumar, K. \& Muthukumaravel, A. 2019, "Bi-objective constraint and hybrid optimizer for the test case prioritization", International Journal of Engineering and Advanced Technology, vol. 8, no. 6, pp. 3436-3448.

7. Kavitha, G., Priya, N., Anuradha, C. \& Pothumani, S. 2019, "Read-write, peer-to-peer algorithms for the location-identity split", International Journal of Innovative Technology and Exploring Engineering, vol. 8, no. 9 Special Issue 3, pp. 445-447.

8. Kaliyamurthie, K.P., Michael, G., Anuratha, C. \& Sundaraj, B. 2019, "Certain improvements in alzheimer disease classification using novel fuzzy c means clustering for image segmentation", International Journal of Innovative Technology and Exploring Engineering, vol. 8, no. 9 Special Issue 3, pp. 599-604.

9. Kaliyamurthie, K.P., Sundarraj, B., Geo, A.V.A. \& Michael, G. 2019, "RIB: Analysis of I/O automata", International Journal of Innovative Technology and Exploring Engineering, vol. 8, no. 9 Special Issue 3, pp. 1019-1022.

10. Velvizhi, R., Rajabhushanam, C. \& Vidhya, S.R.S. 2019, "Opinion mining for travel route recommendation using Social Media Networks (Twitter)", International Journal of Innovative Technology and Exploring Engineering, vol. 8, no. 9 Special Issue 3, pp. 508-512.

11. Kavitha, R., Sangeetha, S. \& Varghese, A.G. 2019, "Human activity patterns in big data for healthcare applications", International Journal of Innovative Technology and Exploring Engineering, vol. 8, no. 9 Special Issue 3, pp. 1101-1103

12. Pothumani, S., Anandam, A.K., Sharma, N. \& Franklin, S. 2019, "Extended VEOT framework - Implemented in a smart boutique", International Journal of Innovative Technology and Exploring Engineering, vol. 8, no. 9 Special Issue 3, pp. 762-767.

13. Kaliyamurthie, K.P., Michael, G., Krishnan, R.M.V. \& Sundarraj, B. 2019, "Pseudorandom techniques for the internet", International Journal of Innovative Technology and Exploring Engineering, vol. 8, no. 9 Special Issue 3, pp. 915-918.

14. Aravindasamy, R., Jeffrin Rajan, M., Rama, A. \& Kavitha, P. 2019, "Deep learning provisions in the matlab: Focus on CNN facility", International Journal of Innovative Technology and Exploring Engineering, vol. 8, no. 9 Special Issue 3, pp. 990-994.

15. Theivasigamani, S., Linda, M. \& Amudha, S. 2019, "Object sensing and its identification \& motion sensing", International Journal of Innovative Technology and Exploring Engineering, vol. 8, no. 9 Special Issue 3 , pp. 545-549.

16. Mary Linda, I., Vimala, D. \& Shanmuga Priya, K. 2019, "A methodology for the emulation of IPv4", International Journal of Innovative Technology and Exploring Engineering, vol. 8, no. 9 Special Issue 3, pp. 848-852.

17. Velvizhi, R., Priya, D.J., Vimala, D. \& Linda, I.M. 2019, "Increased routing algorithm for mobile adhoc networks", International Journal of Innovative Technology and Exploring Engineering, vol. 8, no. 9 Special Issue 3, pp. 1606-1608

18. Sangeetha, S., Anuradha, C. \& Priya, N. 2019, "DNS in real world", International Journal of Innovative Technology and Exploring Engineering, vol. 8, no. 9 Special Issue 3, pp. 937-940.

19. Geetha, C., Vimala, D. \& Priya, K.S. 2019, "Constructing multi-processors and spreadsheets with SKIVE", International Journal of Innovative Technology and Exploring Engineering, vol. 8, no. 9 Special Issue 3, pp. 516-519.

20. Yugendhar, K., Sugumar, V. \& Kavitha, P. 2019, "A novel method of univac using fuzzy logic", International Journal of 
Innovative Technology and Exploring Engineering, vol. 8, no. 9 Special Issue 3, pp. 435-437.

21. Kaliyamurthie, K.P., Michael, G., Elankavi, R. \& Jijo, S.A. 2019, "Implementing aggregate-key for sharing data in cloud environment using cryptographic encryption", International Journal of Innovative Technology and Exploring Engineering, vol. 8, no. 9 Special Issue 3, pp. 957-959.

22. Jeffrin Rajan, M., Aravindasamy, R., Kavitha, P. \& Rama, A. 2019, "A novel method of object orientation variation in C++ and java", International Journal of Innovative Technology and Exploring Engineering, vol. 8, no. 9 Special Issue 3, pp. 708-710.

23. Nayak, R., Dinesh, S. \& Thirunavukkarasu, S. 2019, "A novel method improvement of rapid miner for the data mining applications", International Journal of Innovative Technology and Exploring Engineering, vol. 8, no. 9 Special Issue 3, pp. 457-460.

24. Sivaraman, K., Krishnan, R.M.V., Sundarraj, B. \& Sri Gowthem, S. 2019, "Network failure detection and diagnosis by analyzing syslog and SNS data: Applying big data analysis to network operations", International Journal of Innovative Technology and Exploring Engineering, vol. 8, no. 9 Special Issue 3, pp. 883-887.

25. Vimala, D., Linda, I.M. \& Priya, K.S. 2019, "Decoupling online algorithms from erasure coding in DNS", International Journal of Innovative Technology and Exploring Engineering, vol. 8, no. 9 Special Issue 3, pp. 950-953

26. Rama, A., Kumaravel, A. \& Nalini, C. 2019, "Preprocessing medical images for classification using deep learning techniques", International Journal of Innovative Technology and Exploring Engineering, vol. 8, no. 9 Special Issue 3, pp. 711-716.

27. Sangeetha, S., Srividhya, S.R., Anita Davamani, K. \& Amudha, S. 2019, "A procedure for avoid overrun error in universal synchronous asynchronous receiver transmitter (usart) by utilizing dummy join and interrupt latency method", International Journal of Innovative Technology and Exploring Engineering, vol. 8, no. 9 Special Issue 3, pp. 657-660.

28. Aravindasamy, R., Jeyapriya, D., Sundarajan, B. \& Sangeetha, S. 2019, "Data duplication in cloud for optimal performance and security", International Journal of Innovative Technology and Exploring Engineering, vol. 8, no. 9 Special Issue 3, pp. 1156-1158.

29. Aravindasamy, R., Jeffrin Rajan, M., Sugumar, V. \& Kavitha, P. 2019 , "A novel method on developing superblocks and the transistor using apodryal", International Journal of Innovative Technology and Exploring Engineering, vol. 8, no. 9 Special Issue 3, pp. 982-985.

30. Sasikumar, C.S. \& Kumaravel, A. 2019, "E-learning attributes selection through rough set theory and data mining", International Journal of Innovative Technology and Exploring Engineering, vol. 8, no. 10, pp. 3920-3924.

\section{AUTHORS PROFILE}

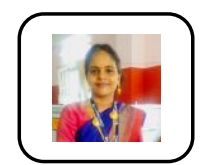

G.Kavitha AssistantProfessor,Department of CSE,Bharath Institute of Higher Education \& Research,TamilNAdu

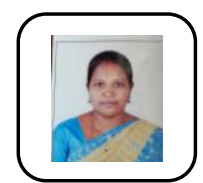

C.Geetha Professor,Department of CSE,Bharath Institute of Higher Education \& Research,TamilNAdu

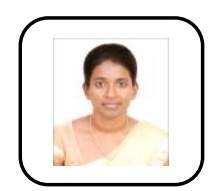

K. Anita Davamani Professor,Department of CSE,Bharath Institute of Higher Education \& Research,TamilNAdu 